\title{
What Prevents Eligible Patients from Receiving Progesterone Therapy to Prevent Recurrent Preterm Birth
}

\author{
Amanda Meyer ${ }^{1}$, Nancy Cipparrone2 ${ }^{2}$ Andrea Buras ${ }^{1}$, Barbara V. Parilla ${ }^{{ }^{*}}$ \\ ${ }^{1}$ The Department of Obstetrics and Gynecology Advocate, Lutheran General Hospital, Park Ridge, \\ Illinois, USA \\ ${ }^{2}$ The Russell Institute for Research \& Innovation Advocate, Lutheran General Hospital, Park Ridge, \\ Illinois, USA \\ Email: ${ }^{*}$ Barbara.Parilla@advocatehealth.com
}

Received 10 April 2014; revised 4 May 2014; accepted 11 May 2014

Copyright (C) 2014 by authors and Scientific Research Publishing Inc.

This work is licensed under the Creative Commons Attribution International License (CC BY). http://creativecommons.org/licenses/by/4.0/ (c) (i)

\section{Abstract}

Objective: The use of intramuscular 17-alpha-hydroxyprogesterone caproate (17-0HPC) has been shown to be beneficial for the prevention of preterm birth (PTB) in women with a prior history. Not all patients with a prior preterm birth receive 17-0HPC. The purpose of this study was to investigate potential barriers to receiving this therapy. Methods: A retrospective chart review of those patients at our institution who received the diagnosis of "previous preterm delivery" in 2010 and 2011 was performed to see whether they were offered and received 17-0HPC. Patients were considered eligible if they had a prior delivery at less than $\mathbf{3 6}$ weeks of gestation secondary to idiopathic preterm labor. For those patients that were deemed eligible but did not receive therapy, an explanation was sought. Results: Sixty-six charts were reviewed in detail. Forty-three patients were considered eligible to receive 17-0HPC. The remaining had medical indications for delivery including premature rupture of membranes (PROM) (15), intrauterine growth restriction (IUGR) (1), and hypertension (2). Of the 43 patients deemed eligible, 17 did not receive 17-0HPC. of these, eight patients were not offered therapy, 2 patients declined therapy, 3 patients presented with therapy after 28 weeks (too late), and 4 received a prophylactic cerclage as their only therapy. There were no significant differences between the two groups. Conclusion: In an effort to increase 17-OHPC use among eligible patients, we must continually identify physician biases and patient barriers that prevent utilization of this intervention. In addition, patients who deliver preterm should be told the importance of presenting early in subsequent pregnancies in order to receive the full benefits of this therapy.

\footnotetext{
${ }^{*}$ Corresponding author.
}

How to cite this paper: Meyer, A., et al. (2014) What Prevents Eligible Patients from Receiving Progesterone Therapy to Prevent Recurrent Preterm Birth. Open Journal of Obstetrics and Gynecology, 4, 395-398. 


\section{Keywords}

\section{Progesterone, Preterm Birth, Preterm Delivery, 17-Alpha-Hydroxy Progesterone Caproate}

\section{Introduction}

Preterm birth is the leading cause of neonatal mortality, responsible for over 1 million deaths annually. In 2010 approximately $12 \%$ of births in the United Stated were preterm. Many studies have shown the value of 17-alpha-hydroxy progesterone caproate (17-OHPC) [1] in significantly reducing the rate of preterm birth in women with a prior preterm delivery. In 2008, ACOG recommended that this therapy be offered to all eligible patients [2]. Our institution adopted a policy to offer progesterone therapy to all eligible women in 2009. Since the use of 17-OHPC has been recommended for patients with a history of prior spontaneous preterm birth by ACOG, and has been adopted as our institutional standard, we set out to evaluate the compliance of our institution with these recommendations as well as to identify barriers contributing to non-compliance.

\section{Materials and Methods}

This study was a retrospective cohort study of women with a prior preterm delivery being cared for at Advocate Lutheran General Hospital, a suburban tertiary care center. The inclusion criteria consisted of a previous preterm delivery less than 36 weeks between January 1, 2010 and December 31, 2011. Exclusion criteria included primigravida, history of prior preterm birth greater than 36 weeks, history of preterm labor but no preterm delivery, history of an indicated preterm delivery for maternal medical complications such as preeclampsia, or preterm birth associated with maternal or fetal complications such as PPROM or IUGR. This study was approved by the Institutional Review Board at Advocate Lutheran General Hospital.

Descriptive statistics were reported on categorical data as number and (percent) and continuous data as mean \pm SD. Independent t-test, Chi-square or Fishers Exact test when necessary was performed to measure statistical differences between 17-OHPC status (given versus not given). A two-tailed p level of 0.05 was considered statistically significant in all analyses. Analyses were performed with SPSS software (release 19.0, International Business Machines, Chicago).

\section{Results}

Figure 1 is a flow-diagram of patient selection. 318 charts were reviewed, and 66 patients met the eligibility criteria. 21 patients were subsequently excluded for having a history of an indicated preterm delivery or medical complication (15 had PPROM, 1 IUGR, 2 HTN, and 3 had other medical indications for delivery (2 with preterm birth after intrauterine fetal demise, 1 with induction of labor for holoprosencephaly). Two patients were not included as the circumstances of their prior preterm deliveries were unclear from their charts. The demographic data is displayed in Table 1.

Of the 43 eligible patients, 26 patients received 17-OHPC, while 17 did not. There were 10 patients who had preterm deliveries for medical indications (not idiopathic PTL) who were given 17-OHPC; these were counted in the progesterone group $(\mathrm{n}=36)$ in accordance with the intent to treat principle.

Of patients with a prior idiopathic preterm birth, 26 of 43 (60.5\%) received 17-OHPC therapy. Of those eligible patients who did not receive progesterone, 8 were not offered the therapy, 3 presented after 28 weeks, 2 declined therapy, and 4 had a prophylactic cerclage as their only form of treatment. The pregnancy and delivery data is compared in Table 2.

Of those patients who were not offered progesterone therapy, it should be noted that one patient had a term delivery following her initial preterm birth, and 5 others had a history of preterm delivery at 34 or 35 weeks. Of these 5 patients, 4 ultimately went on to have full term deliveries (range 37 - 40 wks; mean 38 4/7 wks). For the 5th patient the delivery information was unknown.

\section{Discussion}

The barrier most commonly identified with progesterone therapy to prevent recurrent preterm birth was the practitioner not offering 17-OHPC therapy. This indicates that continued education regarding the indications and 
timing for progesterone may be needed. Progesterone therapy to prevent recurrent preterm birth is optimally initiated between 16 and 20 weeks of gestation, and continued through 36 weeks. However, it has been shown to be of benefit when initiated as late as 26 weeks [3]. Thus, initiation of treatment later in pregnancy due to late entry into prenatal care should be considered. In addition, education of patients at the time of a preterm delivery regarding future pregnancies may help improve compliance with progesterone therapy in future pregnancies. A

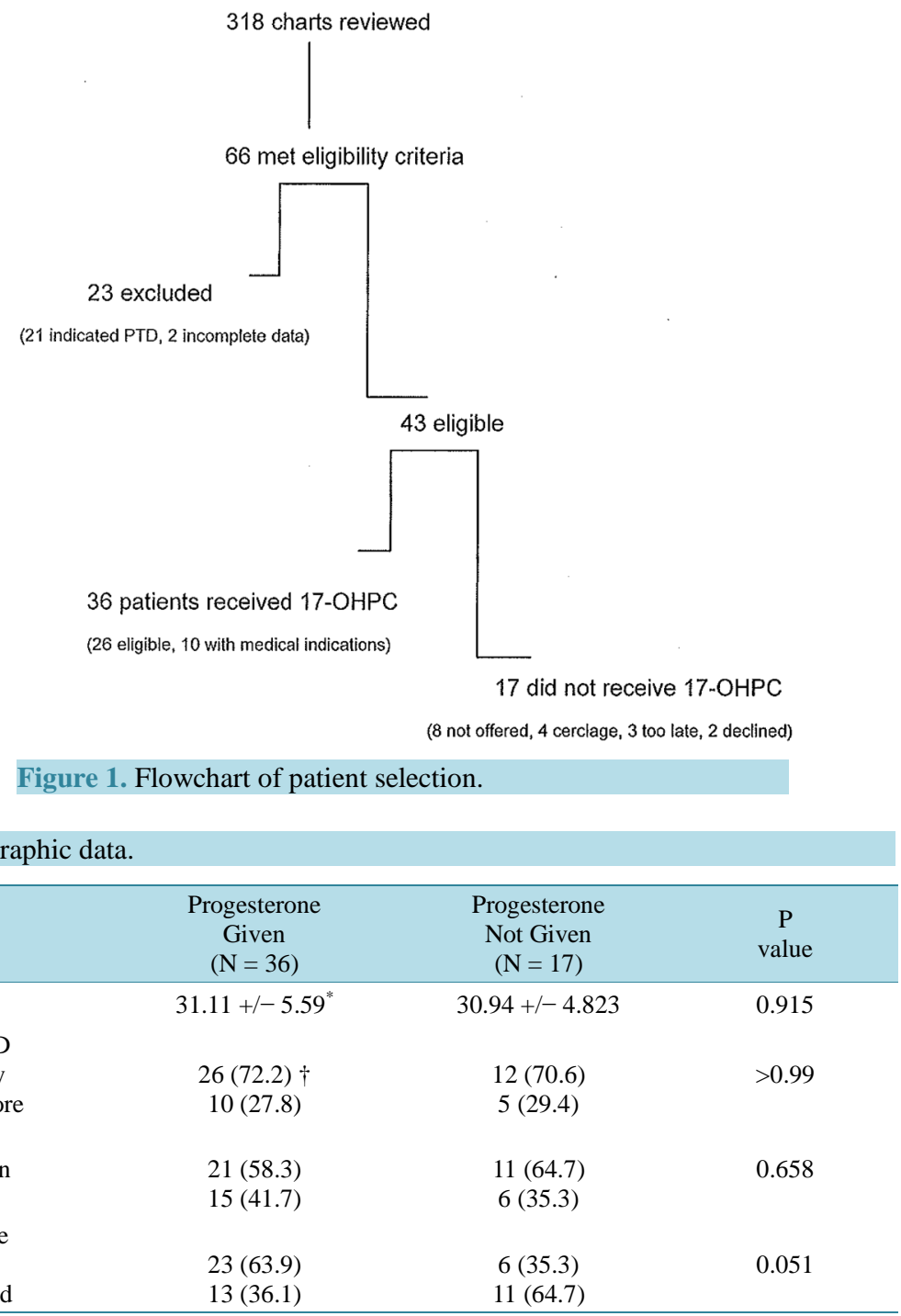

*Mean $\pm \mathrm{SD} ; \uparrow \mathrm{N}(\%) ; \ddagger$ Includes the following races: Hispanic, African American, Pacific Islander, Indian, Asian (not Indian), and Unknown.

Table 2. Pregnancy and delivery results.

\begin{tabular}{cccc}
\hline & $\begin{array}{c}\text { Progesterone } \\
\text { Given } \\
(\mathrm{N}=36)\end{array}$ & $\begin{array}{c}\text { Progesterone } \\
\text { Not Given } \\
(\mathrm{N}=17)\end{array}$ & $\begin{array}{c}\mathrm{P} \\
\text { value }\end{array}$ \\
\hline $\begin{array}{c}\text { Gestational Age at Delivery } \\
\text { Betamethasone } \\
\text { Administered }\end{array}$ & $35.93+/-2.778^{*}$ & $37.41+/-1.75$ & 0.183 \\
Received Tocolysis & 24 & 10 & 0.974 \\
Cerclage Placement & 28 & 9 & $>0.99$ \\
\hline
\end{tabular}

*Mean \pm SD. 
limitation of this study is that since the time this study was initiated, the indications for progesterone therapy have expanded. Progesterone therapy is now recommended for patients with a history of preterm delivery secondary to PPROM and also for cervical insufficiency [4]. This should increase the proportion of eligible patients offered therapy as practitioners feel less burden regarding differentiation of idiopathic preterm labor from cervical insufficiency.

Interestingly, when the first years' data was analyzed, there was a statistically significant difference between those patients that were offered progesterone compared to those that were not based on their payer status (private insurance versus public assistance). However, this difference was no longer significant when the subsequent years' data was included, which was coincident with IDPA expanding coverage of 17-OHPC for this indication.

Four of our patients with a previous late preterm birth (34 - 35 weeks) that were not offered progesterone therapy went on to deliver at term. This is in agreement with an earlier study [5] showing that women with their earliest delivery at 20 to 27.9 weeks and at 28 to 33.9 weeks delivered at significantly more advanced gestational ages if treated with 17-OHPC than with placebo and were less likely to deliver at less than 37 weeks. Those with a previous delivery between 34 and 36.9 weeks were not significantly different between 17-OHPC and control.

In addition to studies reporting the success of 17-OHPC in preventing recurrent preterm delivery, there have been smaller reports on the success of vaginal progesterone for this indication [6]. Subsequently, there has been convincing data on the use of vaginal progesterone for a shortened cervix noted in the index pregnancy, without a previous preterm delivery [7]. What still needs to be studied is a direct comparison of 17-OHPC and vaginal progesterone for the prevention of recurrent preterm birth. This is especially timely given the concern of miscarriage and stillbirth associated with 17-OHPC exposure [8]. Although this finding was noted specifically in twin gestations ( 5 of $164,3 \%$ in exposed versus 0 of 158 in controls, $P=0.06$, Fisher exact test) [9], the increased rate has been noted in singleton pregnancies exposed to 17-OHPC, but the findings were not statistically significant [1]. Additional studies are needed.

\section{References}

[1] Meis, P.J., Klebanoff, M., Thom, E., et al. (2003) Prevention of Recurrent Preterm Delivery by 17-Alpha-Hydroxyprogesterone Caproate. The New England Journal of Medicine, 348, 2379-2385. http://dx.doi.org/10.1056/NEJMoa035140

[2] ACOG Committee Opinion (2008) Use of progesterone to Reduce Preterm Birth. Obstetrics \& Gynecology, 112, 963965, Number 419, October 2008.

[3] How, H.Y., Barton, J.R. and Istwan, N.B. (2007) Prophylaxis with 17 Alpha-Hydroxyprogesterone Caproate for Prevention of Preterm Delivery: Does Gestational Age at Initiation of Treatment Matter? American Journal of Obstetrics \& Gynecology, 197, e1-e4.

[4] Society for Maternal-Fetal Medicine Publications Committee, with Assistance of Vincenzo Berghella (2012) Progesterone and Preterm Birth Prevention: Translating Clinical Trials Data into Clinical Practice. American Journal of Obstetrics \& Gynecology, 206, 376-386.

[5] Spong, C.Y., Meis, P.J., Thom, E.A., et al. (2005) Progesterone for Prevention of Recurrent Preterm Birth: Impact of Gestational Age at Previous Delivery. American Journal of Obstetrics \& Gynecology, 193, 1127-1131. http://dx.doi.org/10.1016/j.ajog.2005.05.077

[6] da Fonseca, E.B., Bittar, R.E., Carvalho, M.H. and Zugaib, M. (2003) Prophylactic Administration of Progesterone by Vaginal Suppository to Reduce the Incidence of Spontaneous Preterm Birth in Women at Increased Risk: A Randomized Placebo-Controlled Double-Blind Study. American Journal of Obstetrics \& Gynecology, 188, 419-424. http://dx.doi.org/10.1067/mob.2003.41

[7] Romero, R., Nicolaides, K., Conde-Agudelo, A., et al. (2012) Vaginal Progesterone in Women with an Asymptomatic Sonographic Short Cervix in the Midtrimester Decreases Preterm Delivery and Neonatal Morbidity: A Systematic Review and Metaanalysis of Individual Patient Data. American Journal of Obstetrics \& Gynecology, 206, 124, e1-e19.

[8] O’Brien, J.M. (2013) Mortality Related to 17-OHPC Exposure Is an Important Safety Outcome. Letter to the Editor. American Journal of Obstetrics \& Gynecology, 209, 282-283. http://dx.doi.org/10.1016/j.ajog.2013.04.028

[9] Senat, M.V., Porcher, R., Winer, N., et al. (2013) Prevention of Preterm Delivery by 17 Alpha-Hydroxyprogesterone Caproate in Asymptomatic Twin Pregnancies with a Short Cervix: A Randomized Controlled Trial. American Journal of Obstetrics \& Gynecology, 208, e1-e8. 